\title{
HAPPINESS ADJUSTED LIFE YEARS (HALY)
}

\author{
Ruut Veenhoven
}

In: Alex C. Michalos (Ed.) Encyclopedia of Quality of Life and Well-Being Research Springer, Dordrecht, Netherlands, 2014. Springer Reference Series, pp. 2641-2643. ISBN 978-94-007-0752-8

DOI: 10.1007/978-94-007-0753-5_c口००

\section{SYNONYMS}

Happy life expectancy (HLE); Happy life years (HLY); Quality adjusted life years (QALY)

\section{DEFINITION}

How long and happy people live. For individuals this can be assessed only once they have died. For populations it can be estimated by combining average happiness as assessed in surveys with average longevity as assessed using civil registration. The focus of this lemma is on happiness adjusted life years in nations.

\section{DESCRIPTION}

How to assess how well a nation is doing? One way is to look at the quality of life of the people who live there. This view is gaining prominence, both among policy makers and the general public. Yet it begs the question of what quality of life is precisely and how it can be measured comprehensively.

\subsection{Assumed Quality of Life}

Quality of life in nations is commonly measured by taking stock of conditions that are believed to make for a better life, such as economic affluence, full employment, and education. Measures of such conditions are added in an index, like the Human Development Index (HDI) or the Index of Social Progress (ISP). Items in such indexes are typically things that are on the political agenda, and as such these indexes provide information about progress on the way chosen. Yet these indexes do not tell us whether we are on the right track, that is, whether these policy achievements really improved the lives of citizens. Still another problem is that such measures typically assume that more is better and do not give us information about optimums, for example, just how many years of education are optimal for a good life. 


\subsection{Apparent Quality of Life}

Another approach to determine quality of life is to assess how well people thrive in a society. The focus is then on the outcomes of life, rather than on the preconditions.

How well an organism thrives is typically reflected in its lifetime. In higher animals, thriving is also reflected in affective experience, and humans are moreover able to estimate how well they have felt over longer periods of time. These estimates of how we feel most of the time form the basis of our appraisal of how happy we are. Hence, in the case of humans, thriving reflects both in how long and how happy they live.

\subsection{Measure of Happy Life Years}

How can we assess how long and happy people live in a country? This can be done by combining data on average happiness assessed in surveys of the general population with data on longevity taken from civil registration.

\section{Happiness}

Happiness is how much one likes the life one lives. Since this is something people have in mind, it can be measured using single direct questions. An example of a survey question on happiness is as follows: Taking all together, how satisfied or dissatisfied are you currently with your life as a whole? This is rated on a numerical scale ranging from 1 (dissatisfied) to 10 (satisfied).

\section{Longevity:}

How long people will live in a country can be estimated on the basis of the longevity data of people who have died. Statisticians call this "life expectancy."

\section{Computation:}

Happy life years $=$ life expectancy at birth x 0-1 happiness. Suppose that life expectancy in a country is 60 years. If everybody was perfectly happy in that country until they died (average score 10), these people would live 60 happy life years in that country. If the average happiness score is 5 , the number of happy life years is obviously lower, in this case $60 \times 0.5=30$. If life expectancy is also 60 years but average happiness is 8 , the number of happy life years is 48 (60 x 0.8) (Veenhoven 1996).

\section{Similar Measures in Health:}

This index of happy life years (HLY) is comparable to measures used in the health sector, referred to as "quality adjusted life years" (QALY). "Quality" is then understood as "health" in a broad sense. Measures of this kind are used at the individual level to determine the effectiveness of different treatments. The measures are also used to assess public health in nations and in this context are called "health-adjusted life expectancy" (HALY) and "disability-adjusted life expectancy" (DALY) (Mathers et al. 1999).

\subsection{Differences Across Nations}

Theoretically, this indicator of final quality of life has a broad variation; HLY is zero if nobody can live in the country and will be endless if a society was ideal and 
its inhabitants immortal. The practical range is about 50 years; the highest number of happy life years observed in the 2010s was for Costa Rica (66.7), and the lowest number was found in Zimbabwe (12.5). Recent data on happy life years in nations are available on the World Database of Happiness (Veenhoven, 2012a).

\section{Gains Over Time}

Happiness has risen slightly in most developed nations since the second half of the twentieth century, and life expectancy has grown substantially. As a result, the number of happy life years has grown remarkably in most nations of the world. The gain of happy life years in Italy was 15.5 between 1973 and 2010. Data on changes in happy life years in nations are available on the World Database of Happiness (Veenhoven, 2012b).

\section{Determinants of Happy Life Years in Nations}

There is a pattern in the differences in happy life years across nations and over time. About two-thirds of the large differences in HLY across nations can be explained by societal variation in economic affluence, freedom, equality, solidarity, and justice, all things over which policy makers have some control. So the data leave no doubt that policy matters for final quality of life and also indicate what matters most. Economic affluence still stands out as a major factor, but "tolerance" and "rule of law" also appear to be quite important. Yet not everything deemed desirable appears to go with more happy life years. For instance, income inequality appears rather to be positively related to HLY, yet social security spending is negatively related. This illustrates the above difference between "assumed" and "apparent" quality of life. 


\section{REFERENCES}

Mathers, C. D., Sadana, R., Salomon, J. A., Murray, C. J., \& Lopez, A. D. (1999)

Healthy life expectancy in 191 countries,

Lancet, 2001, 357(9269), 1685-1691.

Veenhoven, R. (1996)

Happy life-expectancy: A comprehensive measure of quality-of-life in nations.

Social Indicators Research, 39, 1-58.

Veenhoven, R. (2005)

Apparent quality of life: How long and happy people live.

- Social Indicators Research, 71, 61-86.

Veenhoven, R. (2012a)

Happy life years in nations.

World Database of Happiness. Rotterdam: Erasmus University.

Veenhoven, R. (2012b)

Trend happy life years in nations.

World Database of Happiness. Rotterdam: Erasmus University.

\section{Cross-references in encyclopedia:}

Greatest Happiness Principle

Happiness

Quality of life

Quality Adjusted Life Expectancy 